\title{
Enhanced resistance to the rice blast fungus Magnaporthe grisea conferred by expression of a cecropin $A$ gene in transgenic rice
}

María Coca ${ }^{1}$, Gisela Peñas ${ }^{2}$, Jorge Gómez ${ }^{1}$, Sonia Campo ${ }^{1}$, Cristina Bortolotti ${ }^{1}$, Joaquima Messeguer ${ }^{2}$ and Blanca San Segundo ${ }^{1}$.

Laboratorio de Genética Molecular Vegetal, Consorcio CSIC-IRTA; ${ }^{1}$ Departamento de Genética Molecular, Instituto de Biología Molecular de Barcelona, CSIC. Jordi Girona 18, 08034 Barcelona, Spain; ${ }^{2}$ Departamento de Genética Vegetal, IRTA Centro de Cabrils. Carretera de Cabrils s/n, Cabrils 08348, Barcelona, Spain

Corresponding author:

María Coca

E-mail: mclgmb@ibmb.csic.es

Tel: 34934006128

FAX: 34932045904 


\begin{abstract}
Cecropins are a family of antimicrobial peptides which constitute an important key component of the immune response in insects. Here, we demonstrate that transgenic rice (Oryza sativa L.) plants expressing the cecropin A gene from the giant silk moth Hyalophora cecropia show enhanced resistance to Magnaporthe grisea, the causal agent of the rice blast disease. Two plant codon-optimized synthetic cecropin A genes which were designed either to retain the cecropin A peptide in the endoplasmic reticulum, the $E R$-CecA gene, or to secrete cecropin A to the extracellular space, the $A p$ CecA gene, were prepared. Both cecropin A genes were efficiently expressed in transgenic rice. The inhibitory activity of protein extracts prepared from leaves of cecropin A-expressing plants on the in vitro growth of $M$. grisea indicated that the cecropin A protein produced by the transgenic rice plants was biologically active. Whereas no effect on plant phenotype was observed in ER-CecA plants, most of the rice lines expressing the $A p-C e c A$ gene were non fertile. Cecropin A rice plants exhibited resistance to rice blast at various levels. Transgene expression of cecropin A genes was not accompanied by an induction of Pathogenesis-Related $(P R)$ gene expression supporting that the transgene product itself is directly active against the pathogen. Taken together, the results presented in this study suggest that the cecropin $A$ gene when designed for retention of cecropin A into the endoplasmic reticulum, could be a useful candidate for protection of rice plants against the rice blast fungus $M$. grisea.
\end{abstract}

Key words: antifungal, cecropin A, Oryza sativa, rice blast fungus, transgenic rice 


\section{Introduction}

Rice blast disease, caused by Magnaporthe grisea (Hebert) Barr (anamorph Pyricularia grisea Saccardo) is a serious agricultural problem worldwide. $M$. grisea infection results in severe damage and reduced yield of rice plants (Ou 1985). Because of high pathogenic diversity, resistance to blast is not available in cultivated rice varieties. Fungicides are commonly used to control blast. However, this is becoming less acceptable since it increases the potential for the build-up of resistance in $M$. grisea to fungicides and also conflicts with the public concern for fungicide residues on human health and environment. Plant genetic engineering is then regarded as an approach for providing resistance to blast in commercial rice varieties. This approach is advantageous for introducing disease resistance into elite rice cultivars, since transgenic plants can acquire a single desired trait without any alteration of the original genetic background.

Different genetic strategies have been used to generate disease-resistant plants, which include utilization of antimicrobial genes of both plant and non-plant origin, as well as the expression of plant disease-response pathway components (Lorito et al. 1998; Cao et al. 1998; Datta et al. 1999). The best known examples of protection conferred by transgenic expression of plant antifungal genes are represented by overexpression of chitinases and $\beta$-1,3-glucanases (Broglie et al. 1991; Datta et al. 1999). However, the protection provided by a single plant antifungal gene is limited as the degree of resistance is relatively low. Thus, the simultaneous expression of different plant antifungal genes has been found to be necessary to achieve significant levels of protection (Zhu et al. 1994; Jach et al. 1995). Most probably, expression of antifungal genes from plant sources has resulted in modest protection against pathogens because plant pathogens have already evolved tolerance to such plant-derived proteins. In contrast, the expression of genes encoding antimicrobial peptides of animal, fungal or bacterial origin in transgenic plants has proven to confer high levels of protection and broad spectrum of resistance against pathogens (Lorito et al. 1998; Mitsuhara et al. 2000; Osusky et al. 2004).

Antimicrobial peptides are now recognized as an important component of the innate immunity in mammals, insects, amphibians and plants (Boman 1995; Broekaert et al. 
1995; Bohlmann 1999; Zasloff 2002; Castro and Fontes 2005). Certain common structural patterns are found in the antimicrobial peptides so far characterized. Some of them are cationic and amphipathic molecules, such as cecropin peptides, and others contain $\exists$-sheet elements stabilized by intramolecular cystine disulphide bonds as exemplified by plant and insect defensins (Rao 1995; Zasloff 2002). Cecropins are a family of peptides of $35-37 \mathrm{r}^{0} \mathrm{z}<$ esidues in length and highly basic in nature originally isolated from immune hemolymph of the Cecropia moth (Steiner et al. 1981). Included in the general family of cecropins are the homologus peptides from other insect species and mammals (Boman et al. 1995). They are synthesized as precursor proteins, which include an amino-terminal signal peptide for targeting of the preprotein into the secretory pathway. Cecropins have long been demonstrated to possess lytic activity against gram-positive and gram-negative bacteria. The structural features of the cecropins include a strongly basic $\mathrm{N}$-terminus, an intermediate hinge region containing Gly, Pro, or both, and a hydrophobic C-terminus. These features are necessary for their lethal activity, a process that involves the formation of pores across bacterial membranes (Christensen et al. 1988; Steiner 1988; Shai 1999). In contrast, animal and plant cells have been reported to be resistant to the action of cecropins (Nordeen et al. 1992; Mills and Hammerschlag 1993). The basis for these diverse effects of cecropins is thought to be differences in membrane composition and structure (Shai 1999; Silvestro and Axelsen 2000). These characteristics make cecropin peptides attractive tools for developing durable disease resistance against phytopathogens. A number of past attempts to enhance resistance to bacterial pathogens through the expression of cecropin $\mathrm{B}$ genes, however, resulted in contradictory results regarding pathogen resistance (Jaynes et al. 1993; Hightower et al. 1994; Florack et al. 1995; Allefs et al. 1995; Huang et al. 1997; Sharma et al. 2000). In other studies, it was demonstrated that cecropin B peptides are highly susceptible to degradation by endogenous plant proteases. Moreover, the susceptibility of cecropin B peptides to degradation by endogenous proteases varies from one plant species to another (Mills et al. 1994; Owens and Heutte 1997). Together these results reveal that there is no guarantee that a peptide that was effective in one host against one pathogen will be effective in a different host against a different pathogen. 
In this study, we report the stable transformation of an elite japonica rice, Oryza sativa L. cv. Senia, with a plant codon-optimized synthetic cecropin A gene from Hyalophora cecropia (Steiner et al. 1981). Two different strategies were used for engineering the cecropin A gene, in terms of the appropriate subcellular compartment for accumulation of cecropin A, the endoplasmic reticulum or the apoplast. Our results show that constitutive expression of cecropin A in rice plants increased their resistance to the blast fungus $M$. grisea.

\section{Materials and methods.}

Plant and fungal material

Transformation was carried out with the Mediterranean elite japonica rice (O. sativa L.) cultivar Senia. M. grisea (PR09 isolate, CIRAD collection, Montpellier, France) was maintained on rice flour medium (20 g/l rice flour, $15 \mathrm{~g} / \mathrm{l}$ agar and $2.5 \mathrm{~g} / \mathrm{l}$ yeast extract). Spores were collected by adding sterile water to the surface of the mycelium. After filtration, spores were adjusted to the appropriate concentration with sterile water using a Bürker counting chamber.

Construction of the chimeric cecropin A genes and plant expression vectors

Two vectors containing the cecropin A gene were constructed for plant transformation. First, a plant expression vector harbouring a synthetic cecropin A gene designed for secretion of cecropin A via the endoplasmic reticulum to the apoplastic space, the ApCecA gene, was obtained. A second expression vector in which the synthetic cecropin A gene was designed to retain cecropin A in the lumen of the endoplasmic reticulum (ER), the $E R-C e c A$ gene, was prepared. In both constructs, the signal sequence from a secreted plant protein, the tobacco PR1a protein (Cornelissen et al. 1987), was fused to the mature cecropin A sequence to obtain a chimeric cecropin A gene. 
Synthetic cecropin A genes were fully synthesized by recursive PCR (Prodromou and Pearl 1992) using long DNA oligonucleotides. This technique has the potential for the total synthesis of the entire cecropin A gene in a single PCR reaction. Relative positions of the long oligonucleotides used for construction of the quimeric cecropin A genes are shown in Figure 1a. DNA oligonucleotides were synthesized on an Applied Biosystems 394 DNA synthesizer as previously described (Coca et al. 2004). The nucleotide sequence coding for the signal peptide of the tobacco PR-1a protein was fused to the coding sequence for the mature cecropin A protein during the process of oligonucleotide assembly. Similarly, ER retention signal sequence (KDEL tetrapeptide) was fused to the C-terminus of the mature cecropin A during the PCR reaction.

The oligonucleotide sequences were as follows (underlined sequences indicate restriction sites introduced for cloning purposes; sequence in bold corresponds to the nucleotide sequence encoding the KDEL retention signal):

CecA.1 (75-mer):

5’ATAGGGATCCGAGGCCACCATGGGCTTCGTCCTCTTCTCCCAACTCCCATC CTTCCTCCTCGTCTCCACCСTCCT3'

CecA.2 (71-mer):

5’CTTCTTGAAAAGCTTCCACTTGGCGCGGCAGGAGTGGGAGATCACGAGGA ACAGGAGGAGGGTGGAGACGA3’

CecA.3 (71-mer):

5’AAGTGGAAGCTTTTCAAGAAGATCGAGAAGGTCGGCCAAAACATCCGCG ACGGCATCATCAAGGCCGGCCC3’

CecA.4 (73-mer), 5’TATAGGATCCATTATCACTTGGCGATTTGGGTGGCTTGGCCGACGACGGC GACGGCTGGGCCGGCCTTGATGA3’

CecA.5 (85-mer):

5’TATAGGATCCATTATCAGAGCTCGTCCTTCTTGGCGATTTGGGTGGCTTG GCCGACGACGGCGACGGCTGGGCCGGCCTTGATGA3’

The PCR reaction was carried out with $30 \mathrm{pmol}$ of the outer oligonucleotides and 0.2 pm of each internal oligonucleotide using the Expand High Fidelity PCR System (Roche) as previously described (Coca et al. 2004). Subsequent cloning of the synthesized cecropin A genes into the cloning vector for transformation was facilitated 
by the incorporation of the BamHI restriction site in the outermost oligonucleotides. The newly created synthetic cecropin A genes were cloned into the BamHI site of pAHC17 plasmid DNA (Christensen and Quail 1996) under the control of the maize ubiquitin 1 (ubi) promoter (Christensen et al. 1992) and the nopaline synthase (nos) terminator sequences. Finally, the entire cassette for expression of the synthetic cecropin A genes, either the $A p-C e c A$ or the $E R$-CecA gene, was cloned into the Kpn I-digested pCAMBIA 1300 vector, resulting in plasmids $p C u b i:: A p C e c A:$ nos (vector for secretion of cecropin A to the apoplastic space) or $p C u b i:: E R-C e c A:$ nos (vector for retention of the cecropin A in the ER). All constructs used for rice transformation were verified by nucleotide sequencing.

Production of transgenic rice plants

Transgenic rice lines expressing the chimeric cecropin $A$ genes were produced by Agrobacterium-mediated transformation of embryogenic callus derived from mature embryos as described by Pons et al. (2000). The expression vector constructs were transferred to A. tumefaciens EHA105 strain (Hood et al. 1993). The parent pCAMBIA 1300 vector already contains the hptII (hygromycin phospho transferase) gene encoding hygromycin resistance in the T-DNA region. T0 plants were transferred to containment greenhouse conditions and selected on the basis of transgene expression and integration. Homozygous transgenic lines in the T2 generation were identified. Rice plants transformed with the empty vector (pCAMBIA 1300) (Coca et al. 2004) were also used in this work. All rice plants were grown at $27 \forall 2^{\circ} \mathrm{C}$ under 18h/6h light/dark photoperiod.

Southern and Northern blot analyses

DNA was extracted according to the method of Murray and Thompson (1980) but using MATAB (0.1M Tris HCl, pH 8.0, 1.4M NaCl, 20 mM EDTA, 2\% MATAB, 1\% PEG $6000,0.5 \%$ sodium sulphite) as the extraction buffer. DNAs were electrophoresed on 
0.8\% agarose gels, transferred to nylon membranes (Hybond-N, Amersham, UK) and hybridized to ${ }^{32} \mathrm{P}$ labeled DNA probes. Hybridization was carried out in $40 \%$ formamide, 0.25M PBS (1x PBS, $50 \mathrm{mM}$ Na phosphate, $\mathrm{pH} 7.5,0.15 \mathrm{M} \mathrm{NaCl}$ ), 7\% SDS, $10 \%$ PEGs containing $100 \mu \mathrm{g} / \mathrm{ml}$ of salmon sperm DNA, at $42^{\circ} \mathrm{C}$. Membranes were washed to $3 \mathrm{xSSC}, 0.5 \% \mathrm{SDS}$ at $65^{\circ} \mathrm{C}$.

Total RNA was isolated from the leaves of transgenic and control plants as described by Logeman et al. (1987). RNAs were subjected to formaldehyde-containing agarose gel electrophoresis, and transferred to nylon membranes (Hybond-N, Amersham, UK). Hybridizations were performed as described above. All probes were gel purified and radioactively labelled by random priming.

Preparation of plant protein extracts, production of the cecropin A antiserum and immunoblot analysis

For preparation of total protein extracts, leaves were ground to a fine powder in liquid nitrogen and chilled extraction buffer (50 mM Na phosphate buffer, pH 7.0, $20 \mathrm{mM}$ sodium metabisulfate, $2 \mathrm{mM}$ EDTA, $2 \mathrm{mM}$ dithiothreitol, $1 \mathrm{mM}$ phenylmethylsulfonyl fluoride, 1 :M pepstatin and 0.5 :g/ml leupeptin) was added to the powder. Extractions were carried out at $4^{\circ} \mathrm{C}$ for 30 min with continuous slow stirring, followed by centrifugation at $10,000 \mathrm{rpm}$ for $15 \mathrm{~min}$ at $4^{\circ} \mathrm{C}$. All protein concentrations were determined using the Bradford method (1976) with the BioRad dye reagent and bovine serum albumin as a standard.

Polyclonal antibodies against cecropin A were produced in rabbits. For this, the cecropin A (Sigma) was used. Three triweekly injections (50 $\mu \mathrm{g}$ in each injection) were carried out, and the rabbits were bled 8 days after the initial injection. Preimmune serum was collected from the rabbits 1 week before immunization.

For western blotting, fixed amounts of total protein extracts were separated on Tricine-SDS-PAGE (15\%) (Schägger and von Jagow 1987) and transferred onto a PVDF membrane (Immobilon, Millipore). Blots were incubated for $2 \mathrm{~h}$ at room temperature with the anti-cecropin A antiserum diluted 1:500, followed by incubation with anti-rabbit IgG peroxidase-linked antibody from donkey (Amersham Pharmacia 
Biotech, Germany). Detection of antigen-antibody complexes was performed with enhanced chemiluminiscence using ECL ${ }^{\mathrm{TM}}$-kit (Amersham Pharmacia Biotech).

Immunolocalization of cecropin A

Rice seeds from wild-type and T2 homozygous transgenic lines, R26-14 (Ap-CecA) and R33-7 (ER-CecA) lines, were sterilized and germinated for two days in water. Radicles were cut in small pieces using a razor blade and inmediately fixed with $4 \%(\mathrm{w} / \mathrm{v})$ paraformaldehyde in PBS by vacuum infiltration for 1 hour at room temperature. After one change, the radicle tissues were kept in the fixation solution overnight at $4^{\circ} \mathrm{C}$. Tissues were then washed three times with PBS buffer. The material was dehydrated in a graded series of ethanol, infiltrated in a graded series of Histo-clear ${ }^{\mathrm{TM}}$ II (National Diagnostics) and embedded in paraffin (Paraplast Plus, Sigma). Serial sections ( $8 \mu \mathrm{m}$ thick) from paraffin-embedded material were mounted on glass slides pre-coated (Fisherbrand ${ }^{\circledR}$ ). Paraffin was removed from tissues by incubating the slides in Histoclear $^{\mathrm{TM}}$ twice for $10 \mathrm{~min}$ each. Then, tissues were rehydrated in ethanol:water series. All washes and incubations with antibodies were performed in PBST (PBS buffer and 0.1 \% Tween 20 containing 3\% skim milk powder). Sections were blocked for 1 hour at room temperature, incubated with a 1:100 dilution of the anti-cecropin A antiserum overnight at $4^{\circ} \mathrm{C}$, washed three times and incubated with a donkey anti-rabbit IgG antibody conjugated to Alexa Fluor ${ }^{\circledR} 555$ (Molecular Probes, Inc.) diluted 1:1000 in PBST for $60 \mathrm{~min}$ at room temperature. Slides were mounted with Mowiol ${ }^{\circledR}$ reagent (Calbiochem). Immunofluorescent images were collected with the Leica TCS SP microscope.

In vitro bioassays

In vitro antifungal assays with rice protein extracts from transgenic, control untransformed plants and plants transformed with the empty vector were performed using the microtitre plate inhibition assay described by Cavallarin et al. (1998). Total 
protein extracts were prepared from rice leaves using $50 \mathrm{mM}$ Tris $\mathrm{HCl}, \mathrm{pH}$ 7.5, $50 \mathrm{mM}$ $\mathrm{NaCl}$ as the extraction buffer. The effect of intercellular fluids (ICFs) was also assayed. The ICFs were obtained from rice leaves by vacuum infiltration with $0.3 \mathrm{M}$ sucrose, 0.3 mM HEPES buffer, pH 5.7. Infiltrated leaves were then centrifuged (2000 g for $5 \mathrm{~min}$ ) and the ICF collected. After extraction of ICFs, the remaining leaf tissues were extracted to obtain the intracellular proteins.

For the in vitro antifungal activity assays, $M$. grisea spores were pregerminated for $8 \mathrm{~h}$ in $50 \mu$ of potato dextrose broth (PDB) and the absorbance was determined. The protein samples (50 $\mu \mathrm{l}$, containing $100 \mu \mathrm{g}$ of total protein extracts or $20 \mu \mathrm{g}$ of proteins from ICFs and intracellular proteins), were then added to the wells. The plate was incubated at $28^{\circ} \mathrm{C}$ for the required period of time, and the absorbance was read (OD 595 $\mathrm{nm}$ ). Experiments in which the antifungal activity of the cecropin A peptide (Sigma Chemical, St Louis), either alone (2, 4 and $10 \mu \mathrm{M})$ or in combination with total protein extracts from leaves of control untransformed plants $(100 \mu \mathrm{g})$, were also performed with the microtiter plate assay. Three independent experiments with separate preparations of each plant protein extract, and three replicas for each protein extract were made.

In vivo bioassays

To test resistance to $M$. grisea infection of transgenic plants, infection of detached leaves with different doses of $M$. grisea spores was performed as previously described (Coca et al. 2004). Briefly, the second leaf of 2-week old soil-grown rice plants were placed into plate dishes with $1 \%$ w/v water agar containing $2 \mathrm{mg} / \mathrm{l}$ kinetine. Whatmann filter paper discs saturated with a $M$. grisea PR9 spore suspension at the appropriate concentration were placed onto the upper face of the leaf for $36 \mathrm{~h}$ and then removed. The inoculated leaves were maintained in chamber under humid conditions at $28^{\circ} \mathrm{C}$ under $16 \mathrm{~h}$ light and $8 \mathrm{~h}$ dark for the required period of time. Development of disease symptoms with time was followed. Six independent T2 homozygous ER-CecA lines and three $A p-C e c A$ lines, and at least ten plants for each line were assayed. Blast resistance was measured by counting the number of spores from control and transgenic lines, as well as by estimating the leaf area covered with lesions. Spores were harvested from 
infected leaves in $1 \mathrm{ml}$ of steril water. The infection was quantified 6 days after infection using a Bürker counting chamber to count three aliquots (10 $\mu \mathrm{l})$ of each sample.

Trypan blue staining was used to confirm fungal colonization. For this, the fungalinoculated leaves were fixed with formaldehyde (ethanol-formaldehyde-acetic acid, 80:3.5:5 v/v) by vacuum infiltration for 1 hour at room temperature. After one change, the tissue was kept in the fixation solution overnight. The plant material was then stained with lactophenol blue solution for 6 hours at room temperatute, washed with water and observed with a Zeiss Axiophot microscope (Carl Zeiss, Thornwood, NY, USA) under bright-field illumination.

Evaluation of resistance to blast of cecropin A-expressing rice plants was also assayed by spraying soil-grown control and transgenic rice plants with $M$. grisea spores. Plants at the three-leaf stage were sprayed with a spore suspension $\left(10^{4}\right.$ spores per $\mathrm{ml}$, containing $0.02 \% \mathrm{v} / \mathrm{v}$ Tween 20 ) until leaves were covered with fine droplets. Following inoculation, the plants were maintained in a dew chamber with $95 \%$ relative humidity at $27 \forall 2^{\circ} \mathrm{C}$ under $18 \mathrm{~h} / 6 \mathrm{~h}$ light/dark photoperiod. Development of symptoms was monitored visually. These experiments were carried out at least three times with the three independent lines harbouring either the $E R-C e c A$ or the $A p-C e c A$ gene, to confirm the reproducibility of the results.

\section{Results}

Construction of vectors for expression of cecropin A genes in transgenic rice plants

Based on the amino acid sequence of cecropin A from the cecropia moth, $H$. cecropia (Steiner et al. 1981), two codon-optimized cecropin A genes, which were designed to target cecropin A either to the apoplast (Ap-CecA gene) or to the endoplasmic reticulum (ER-CecA gene) were chemically synthesized (Fig. 1a). In order to allow the cecropin A to enter the secretory pathway of the rice cell, the signal peptide of the $P R$ - $1 a$ gene from tobacco was fused to the mature cecropin A in the two cecropin A genes prepared in this 
work. The ER-CecA gene also contained the KDEL extension for retention in the ER at the C-terminus of the mature cecropin A.

In order to fulfill the preferred codon usage in Oryza sativa (Liu et al. 2004), several modifications were made in the nucleotide sequence coding for the mature cecropin A. Basically, the modifications made for optimization of the codon usage of cecropin $A$ genes were as follows. In the insect cecropin A sequence, 3 out of the 7 lysine residues are encoded by AAA, a codon rarely used for lysine in rice plants. Accordingly, these codons were changed to the codon AAG in the synthetic cecropin gene. Other changes introduced were in the codons for isoleucine (ATT in the insect gene, ATC in the synthetic gene), valine (GTT in the insect gene, GTC in the synthetic gene), threonine (ACA in the insect gene, ACC in the synthetic gene) or glycine (GTT in the insect gene, GGC in the synthetic gene). A total of 21 nucleotides were changed resulting in 20 out of 37 codons of the cecropin A nucleotide sequence modified. The overall $\mathrm{G}+\mathrm{C}$ content of the modified gene is $59.5 \%$ while that of the original cecropin A gene is $46.8 \%$.

Synthetic cecropin A genes were cloned under the control of the maize ubiquitin 1 promoter and the nos terminator. The components of plasmids pCubi::Ap-CecA::nos (vector for secretion of cecropin A to the apoplast) and $p C u b i:: E R-C e c A:: n o s$ (vector for retention of cecropin A into the ER) used for rice transformation are shown in Figure 1b.

Production and molecular characterization of transgenic rice plants

Transgenic rice plants were produced by Agrobacterium-mediated transformation, using the hygromicin resistance gene as the selectable marker. A total of 28 and 17 T0 hygromycin-resistant rice plants harbouring the $u b i:: E R-C e c A::$ nos vector or the ubi::Ap-CecA::nos vector, respectively, were generated.

To examine the expression of the cecropin A gene in trangenic rice plants, Northern blot analysis of T0 hygromicin resistant plants was performed. This analysis revealed that 16 out of 17 Ap-CecA (R26 code) plants, and 23 out of 28 ER-CecA (R33 code) plants accumulated cecropin A transcripts in their leaves and at different levels (Fig. 2). These results indicated that the cecropin A gene is efficiently transcribed into an $m R N A$ 
of the expected size in leaves of $E R-C e c A$ and $A p-C e c A$ rice plants. No effect on plant morphology or fertility was observed in ER-CecA expressing rice lines. In contrast, most of the primary transformants obtained with the $u b i:: A p-C e c A: n o s$ construct were found to be non fertile. Representative T0 ER-CecA and Ap-CecA events accumulating cecropin A mRNA at different levels were selected as the parental lines to obtain T2 homozygous progeny plants.

The copy number and integration patterns of the transgene were determined by Southern blot analysis of genomic DNA obtained from the primary transformants. Transgenic rice lines contained 1-2 insertions of the transgene (results not shown). Stability of transgene integration and inheritance of the ER-CecA and ApCecA transgenes to the progeny was also monitored by Southern blot analysis (results not shown).

Accumulation of cecropin A in rice plants

In order to detect the presence of cecropin A produced in transgenic rice plants, polyclonal antibodies against commercial cecropin A were prepared. In total protein extracts prepared from leaves of the T2 homozygous transgenic lines, the anti-cecropin A antibody reacted with a polypeptide species with a mobility of $8 \mathrm{kDa}$, which was absent in protein extracts from control untransformed plants (Fig. 3a). Cecropin A either alone (Fig. 3a, CecA line) or mixed with protein extracts from control plants (results not shown) was run in parallel with protein extracts from transgenic rice plants. The monomer size of cecropin $\mathrm{A}$ is expected to be $4.0 \mathrm{kDa}$ (mass spectrometry analysis confirmed a mass of 4062.95 for the cecropin A peptide used in this study, results not shown). In addition to the $4.0 \mathrm{kDa}$ band, a minor band at $8.0 \mathrm{kDa}$ was detected in the protein gel blot analysis of the cecropin A peptide. This $8.0 \mathrm{kDa}$ band comigrated with the cecropin A peptide that is immunologically detected in protein extracts from cecropin A-expressing rice lines (Ap-CecA and ER-CecA lines) (Fig. 3a). A dimer of cecropin A might well explain the mobility observed for the cecropin A peptide in total protein extracts from rice and in the cecropin A sample. A similar observation has been previously reported in transgenic tobacco plants expressing the $4 \mathrm{kDa}$ sarcotoxin IA 
peptide, an antibacterial peptide from Sarcophaga peregrina that is structurally related to cecropins (Mitsuhara et al. 2000). Both peptides, Cecropin and sarcotoxin IA peptides, consist of two amphiphilic $\alpha$-helical regions with a hinge region between them (Iwai et al. 1993, Silvestro and Axelsen, 2000). It has been proposed that these peptides may be more stable as a dimer at a low concentration.

By using the Tricine-SDS-PAGE system for electrophoretic separation of total protein extracts from rice leaves, we could detect differences in mobility of the cecropin A peptide produced in $E R-C e c A$ or in $A p-C e c A$ lines. Thus, the band corresponding to the cecropin A peptide expressed in ER-CecA plants showed a slightly higher molecular weight (lines R33 in Fig. 3a). The presence of the C-terminal extension corresponding to the KDEL retention signal, which is present in ER-CecA but not in the Ap-CecA peptide, could account for this different mobility. By comparing the band intensities of $A p$-CecA lines (R26 code) with those of $E R$-CecA (R33 code) lines, it appears that ERCecA plants accumulated slighly higher levels of the cecropin A peptide in leaf tissues. Among the ER-CecA lines here analyzed, line R33-7 consistently accumulated the highest levels of cecropin A peptide. Finally, no immunological reactions occurred with the protein extracts from rice plants when the preimmune serum was used (results not shown).

The level of mRNA and protein accumulation of the T2 homozygous ER-CecA and Ap-Cec A lines was compared. Overall, the level of mRNA accumulation in the transgenic lines harbouring the $E R-C e c A$ gene (R33 code) was slightly higher than that of the rice lines harbouring the Ap-CecA gene (R26 code) (Fig. 3b). Thus, there was a correlation between mRNA and protein accumulation in Ap-CecA and ER-CecA transformants.

In other studies, transgenic plants constitutively expressing certain transgenes have shown to have activated the plant defense mechanisms which are normally activated only during pathogenesis (Mittler et al. 1995). In this respect, expression of $P R-1$ type genes has been widely used as an indicator for induction of defense responses. To explore a possible activation of the plant defense system in the transgenic rice lines, the expression of the endogenous $P R-1$ gene was analyzed at the RNA level in cecropin lines, without pathogen challenge. Transcripts for PR-1 were not detected in transgenic 
lines, either in Ap-CecA or in ER-CecA lines (Fig. 3c). As expected, PR-1a transcripts were detected in M. grisea infected Senia plants (Fig. 3c, lane I).

To examine whether the signal peptide preceding the mature cecropin A peptide allows translocation of cecropin A into the ER and secretion of this peptide to the apoplast, immunolocalization experiments were carried out. Examination of sections prepared from the radicle of $\mathrm{Ap}$-Cec $A$ lines by fluorescence confocal microscopy revealed that the anti-cecropin A antiserum predominantly labeled the intercellular spaces (Fig. 4a, b). Observations of sections prepared from radicles of ER-CecA lines (Fig. 4c) or from control untransformed rice plants (Fig. 4e) did not reveal the characteristic immunolabeling of the apoplast. Equally, sections incubated with preimmune serum did not show any staining at the intercellular spaces (Fig. 4g). The morphology of transverse sections of rice radicles is conveniently observed by transmission microscopy (Fig. 4d, f, h). Thus, confocal microscopy demonstrated the apoplastic location of cecropin A peptide in Ap-CecA rice lines.

Biological activity of cecropin A from transgenic rice plants

To investigate whether the in planta-produced cecropin A exhibited antifungal activity, the ability of protein extracts to inhibit growth of $M$. grisea was determined. Initially, fungal growth inhibition mediated by the cecropin A peptide was examined (Fig. 5a, white bars). The presence of the cecropin A peptide at a concentration of $2 \mu \mathrm{M}$ resulted in $28 \%$ of inhibition of the $M$. grisea growth. Increasing the concentration of the cecropin A peptide up to a concentration of $10 \mu \mathrm{M}$ resulted in $45 \%$ of fungal growth inhibition.

In order to determine to what extent cecropin A-degrading activities could be present in rice leaf tissues, the cecropin A peptide was incubated with protein extracts from control wild-type rice plants. Next, antifungal assays of these mixtures were performed. The inhibitory activity of the cecropin A was not significantly affected (Fig. 5a, black bars), supporting the stability of cecropin A in the presence of rice protein extracts.

Next, the antifungal activity of the cecropin A produced in transgenic rice plants was assessed (Fig. 5b). For this, proteins from leaves of both ER-CecA and Ap-CecA lines 
were extracted. Incubation with total protein extracts from transgenic lines at a concentration of $0.5 \mu \mathrm{g} / \mu \mathrm{l}$ resulted in $19-27 \%$ inhibition of $M$. grisea growth. Protein extracts from untransformed plants (Fig. 5b, WT) or from plants transformed with the empty vector (pCAMBIA 1300, results not shown) did not display antifungal activity.

Finally, the in vitro assay procedure was used to determine the antifungal activities present in the intercellular fluids (ICFs) of cecropin A-expressing rice lines. The levels of fungal inhibition observed with the ICFs where compared with those obtained with the intracellular proteins (proteins extracted from leaf tissues after collecting the ICFs) for each transgenic line (Fig. 5c, d). Intercellular fluids from Ap-CecA plants exhibited antifungal activity (Fig. 5c, Ap-CecA lines), while no antifungal activity was detected with the intracellular protein fraction of the corresponding Ap-CecA line (Fig. 5d, Ap$C e c A$ lines). In the $E R-C e c A$ lines, however, the intracellular protein fraction retained its inhibitory activity after extraction of ICFs from leaves (Fig. 5d, ER-CecA lines).

Together, the antifungal activity assays clearly indicated that the cecropin A produced by the transgenic rice plants was biologically active and inhibited the growth of $M$. grisea. Results observed in these assays with ICFs also support the fact that cecropin A accumulates in the apoplast in the Ap-CecA lines while it is retained intracellularly in the $E R-C e c A$ rice lines.

Resistance to blast of cecropin A rice plants

The rice cultivar Senia used in this study for transformation was previously shown to be highly susceptible to infection by the $M$. grisea PR9 isolate (Coca et al. 2004). Resistance to blast of cecropin $A$ lines was first determined in detached leaves inoculated with increasing doses of $M$. grisea spores. Leaves from six independent T2 homozygous ER-CecA lines (lines R33-1, R33-4, R33-6, R33-7, R33-18 and R33-24) and five independent homozytous Ap-CecA lines (lines R26-2, R-26-5, R26-8, R26-9 and R26-14 lines), as well as from control untransformed plants were assayed. Differences in the degree of disease symptoms caused by $M$. grisea between cecropin A and untransformed plants were clearly observed (Fig. 6a). At a concentration of inoculum of $3 \times 10^{6}$ spores, lesions on control leaves appeared 2-3 days after inoculation 
(dpi) whereas no detectable disease symptoms were observed in leaves of cecropin A lines maintained under the same experimental conditions (results not shown). In control plants, these lesions developed actively. At 7 days after inoculation, leaves from control plants were visibly damaged, whereas cecropin A lines appeared to be much healthier (Fig. 6a). Overall, results obtained in detached leaf assays demonstrated that rice plants expressing cecropin A, both ER-CecA and Ap-CecA rice lines, showed resistance to rice blast at various levels. Among the six ER-CecA lines here assayed, lines R33-24, R33-7 and R33-18, exhibited better control than the other ER-CecA lines. The Ap-CecA line R26-14 showed better protection than any of the other Ap-Cec A lines.

Furthermore, trypan blue staining and microscopical observations of M.griseainfected rice leaves revealed extensive fungal colonization in leaves from control wildtype plants. Significant sporulation was also observed on these leaves (Fig. 6b, left panel). In contrast, under the same experimental conditions no fungal colonization was observed in leaves of the cecropin A lines, either Ap-CecA or ER-CecA lines (Fig. 6b, middle and right panels, respectively). Only few hyphae showing abnormal morphology were detected in the leaf tissue of cecropin A-expressing lines. In all of these pathogen tests, control transgenic plants transformed with the empty vector (pCAMBIA 1300) showed results essentially similar to those of wild-type plants (results not shown).

Resistance of transgenic plants was further determined by counting the number of spores produced in infected leaves and by measuring the size of blast lesions. The results are summerized in Table 1. Transgenic lines, both Ap-CecA and ER-CecA lines, produced a significant lower number of spores and exhibited considerably smaller blast lesions compared to control untransformed plants.

To verify the results obtained by using the detached leaf assay, in vivo inoculation experiments were carried out. For this, rice plants were sprayed with $M$. grisea spore suspensions. Results from these experiments show that the transgenic lines showed enhanced resistance to $M$. grisea infection (Fig. 7). Transgenic lines consistently performed better than controls. A strong difference in plant growth between control and transgenic rice was observed about 3-4 weeks after spraying soil-grown rice plants with fungal spores. In fact, the visual differences in performance between control and transgenic plants were striking at 30 days after inoculation with $M$. grisea spores. By this time, almost all of the control plants had died and the few surviving control plants 
were noticeably retarded in their growth (Table 1). The cecropin A lines, however, remained healthy and showed minimal leaf damage. The ER-CecA lines appear to show better control to blast than $A p-C e c A$ rice lines. Together, blast disease assays demonstrated that constitutive expression of cecropin $A$ in rice confers protection to the blast fungus M. grisea.

\section{Discussion}

Success in the development of new plant cultivars with enhanced resistance to pathogens involving transgenic expression of antifungal genes depends on the nature of the recipient plant, the specific pathogen, and the source of the gene to be used as transgene. In this study, transgenic rice plants constitutively expressing a synthetic version of the cecropin A gene from $H$. cecropia were generated by Agrobacteriummediated transformation. The cecropin A gene was chosen for genetic improvement of rice because previous studies indicated that cecropin A-derived peptides possess in vitro antifungal activity against several agronomically important fungal pathogens (Cavallarin et al. 1998). The mediterranean elite japonica rice cultivar Senia, which is known to be susceptible to the PR9 M. grisea isolate, was used in this study. Results here presented indicated that constitutive expression of the cecropin A gene in rice results in enhanced resistance against $M$. grisea. To our knowledge, the cecropin A gene has not been succesfully used to engineer resistance to pathogens in transgenic plants. Only, the constitutive expression of a chimeric cecropin A gene in which the signal peptide of the cecropin B gene was fused to the mature cecropin A peptide in transgenic tobacco has been reported (Hightower et al. 1994). These trangenic tobacco plants showed no resistance to the bacteria Pseudomonas syringae pv tabaci.

Another insect cecropin peptide, cecropin B, has gained a lot of attention from plant biotechnologists because of the high in vitro toxicity against an important number of plant pathogenic bacteria (Mills and Hammerschlag 1993; Shai 1999). There are a number of reports in the literature in which transgenic expression of cecropin $B$ genes 
has been approached. However, the expression of cecropin B genes revealed variable and contradictory results regarding pathogen resistance (Jaynes et al. 1993; Florack et al. 1995; Huang et al. 1997; Sharma et al. 2000). Thus, transgenic expression of cecropin B from $H$. cecropia in tobacco plants, when designed for secretion into the the extracellular space, did not confer resistance to bacterial infections (Florack et al. 1995). Contrary to this, transgenic rice plants expressing the cecropin $B$ gene from Bombyx mori, also engineered to secrete cecropin B to the extracellular space, conferred enhanced resistance to bacterial leaf blight (Sharma et al. 2000). Failure to obtain pathogen resistance was found to be the consequence of proteolytic degradation of cecropin B peptides by plant proteases present in the intercellular spaces (Mills et al. 1994). In this work, two synthetic versions of the cecropin A gene, which were designed for secretion of cecropin A to the apoplastic space or for retention of cecropin A in the ER, were prepared. The rational of the second approach was to protect the cecropin peptide from potential cecropin A-degrading proteolytic activities from the intercellular spaces. On the other hand, differences in codon usage between insect and plant genes might well limit the expression of a particular insect gene in transgenic plants. Accordingly, plant codon-optimized cecropin A genes were prepared and used for rice transformation.

The two synthetic plant codon-optimized cecropin A genes, the Ap-CecA or the ERCecA gene, were efficiently expressed in leaves of transgenic rice plants. Western blot analysis of total protein extracts from cecropin A-expressing lines provided evidence that cecropin A accumulated in both, Ap-CecA and ER-CecA rice plants. The level of accumulation of the cecropin A peptide detected in total protein extracts prepared from leaves of transgenic lines was, however, low. This low level of cecropin A accumulation might well reflect difficulties in western blot analysis and immunodetection. Similar results have been reported for immunological detection of other short, basic hydrophobic peptides trangenically expressed in plants (Osusky et al. 2004). During the course of this work, western blot analysis of proteins obtained from the intercellular wash fluid of leaves from cecropin A lines was also approached, with no success.

To test the functionality of the plant-produced cecropin A peptide, protein extracts from leaves of transgenic plants were assayed for their ability to inhibit M. grisea 
growth. Total protein extracts from transgenic rice plants, ER-CecA and Ap-CecA plants, showed antifungal activity against $M$. grisea, as judged by in vitro antifungal assays. The antifungal potency of protein extracts from cecropin A-expressing rice plants was similar to that observed in the case of the cecropin A peptide in the in vitro assay. Furthermore, antifungal activity of ICFs obtained from Ap-CecA lines was demonstrated. After removal of the apoplastic fluid from leaves of Ap-CecA lines, no antifungal activity was detected in protein extracts prepared from the remaining leaf tissues. In ER-CecA lines, however, the antifungal activity was retained in the intracellular protein fraction which is prepared from leaf tissues after collecting the apoplastic fluid. Together, these results demonstrated that leaves from transgenic rice plants contained biologically active cecropin A and suggest that cecropin A was properly secreted outside cells in the $A p-C e c A$ plants, while retained intracellularly in the ER-CecA plants. Confirmation of the extracellular location of cecropin $\mathrm{A}$ in $\mathrm{Ap}$ CecA plants came from immunohistochemical localization studies in sections prepared from radicles of $A p-C e c A$ plants. Thus, the immunohistological observations revealed the apoplastic location of cecropin A and confirmed that the $\mathrm{N}$-terminal signal sequence of the tobacco PR-1 protein directs secretion of cecropin A to the intercellular spaces. No such apoplastic location was ever observed in sections prepared from ER-CecA rice plants. Further studies are, however, required to determine the subcellular localization of cecropin A in ER-CecA rice plants, namely whether cecropin A localizes to the endoplasmic reticulum.

Resistance to the rice blast of ER-CecA and Ap-CecA plants was demonstrated using both the detached leaf and the whole plant assays. Further strong support of resistance to blast was obtained by trypan blue staining of infected leaves where growth suppression and anomalies of the fungal hyphae was observed on leaves of the transgenic lines. The detached leaf assay was found to be useful for the screening of blast resistance of a large number of plants from independent transgenic lines. Among the transgenic plants analysed using the detached leaf assay, different levels of resistance to the pathogen were observed. The transgenic lines R33-24, R33-7 and R3318 harbouring the $E R-C e c A$ gene, as well as the R26-14 line expressing the Ap-CecA gene, showed the highest levels of resistance. Definitive proof of resistance of rice lines harbouring the cecropin A gene, either the ER-CecA or the Ap-CecA gene, came from 
blast resistance studies by inoculating whole plants with $M$. grisea spores. In these experiments, the $E R$-CecA lines harbouring the cecropin $A$ gene designed for retention of cecropin A in the ER exhibited better control of blast disease than the Ap-CecA lines in which cecropin A is secreted to apoplast. That the transgene product itself does not influence the expression of endogenous defense mechanisms is supported by the observation that no expression of the endogenous $P R-1$ gene is observed in cecropin $A$ rice lines in the absence of the pathogen. Collectively, our molecular and phenotypic data evidence that the enhanced resistance observed in cecropin A-expressing rice plants is the result of the antifungal activity of cecropin A.

In this work, in vitro antifungal activity assays performed with cecropin A revealed a limited degree of inhibition of $M$ grisea growth (only $45 \%$ of $M$. grisea growth could be inhibited at concentrations of cecropin A of $10: \mathrm{M})$. Traditionally, determination of the antifungal activity of proteins and peptides, as judged by its activity by in vitro antifungal assays have provided an indication of the potency of such proteins or peptides. The $\mathrm{IC}_{50}$ values (concentrations required for 50\% growth inhibition) reported for the inhibition of fungal growth by proteins and peptides using in vitro antifungal assays are in the low micromolar range (Molina et al. 1993; Vila et al. 2001; Moreno et al. 2003). Interestingly, blast disease assays clearly showed enhanced resistance of cecropin A-expressing rice plants to the rice blast fungus $M$. grisea. Clearly, the low antifungal potency of the cecropin A peptide observed in our in vitro antifungal assays does not correlate with the effectiveness of this peptide in the in vivo situation.

The present study provides in vivo evidence for functional differences between the two experimental strategies used for engineering the cecropin A gene used for rice transformation, in terms of the more appropiate subcellular compartment for accumulation of the transgene product, the endoplasmic reticulum or the apoplast. Whereas, functional expression and fertile transgenic plants were achieved by targeting cecropin A into the ER, most of the plants harbouring the construct designed for targeting cecropin A to the apoplastic space were not fertile. From these results it can be concluded that expression of the cecropin A gene from $H$. cecropia in transgenic rice plants, when designed for retention into the ER, is a promising tool in controlling the blast fungus $M$. grisea. It remains to be determined whether expression of the cecropin A gene in transgenic rice confers resistance against diseases caused by other pathogens 
(i.e. Xanthomonas oryzae). Further efforts are in progress to optimize the expression of the cecropin A gene by using a strong, pathogen-inducible promoter in developing transgenic plants resistant to the rice blast fungus. On the other hand, when designing protective strategies involving expression of cecropin genes in crop plants, the possibility of toxicity to humans and animals must be considered. In addition to pathogen-inducibility, the use of a promoter that does not direct transgene expression in the rice endosperm, the eatable organ of the rice plant, represents a more desirable strategy. A number of reports in the literature, however, suggest that cecropins are relatively non-toxic to mammalian cells (Boman and Steiner 1981; Jaynes et al. 1988; Reed et al. 1997). More recently, a cecropin A-melitin hybrid peptide has proven to be effective for treatment of canine leishmaniasis (Alberola et al. 2004). In other studies, no toxic effect of the MsrA1 peptide, another cecropin A-mellitin chimera, was observed on mice fed on tubers from trangenic potato plants constitutively expressing msrA1(Osusky et al. 2000). Finally, the increased levels of disease resistance observed in cecropin A rice plants under controlled conditions need to be confirmed by further evaluation under field conditions and with different races of pathogens.

Acknowledgements. M.C. is a researcher from the Ministerio de Educación y Ciencia (Ramón y Cajal). G.P. is a recipient of a predoctoral fellowship from the Generalitat de Catalunya. We thank Dr U. Schaffrath for providing us with the PR1a rice cDNA probe. We are grateful to A.B. Moreno and M. Rufat for their collaboration in parts of this work and to P. Fontanet for taking care of the greenhouse plants. We also acknowledge Dr. R. Eritja for synthesis of oligonucleotides and Dr. D. Tharreau for providing us with the M. grisea PR9 isolate. This research was supported by the European Commission (QLRT-CT99-1484, EURICE) and by the Ministerio de Ciencia y Tecnologia (BIO2003-04936-C02). We also thank the "Centre de Referència en Biotecnología" (CeRBa) for substantial support. 


\section{References}

Alberola J, Rodrigued A, Francino O, Roura X, Rivas L, Andreu D (2004) Safety and efficacy of antimicrobial peptides against naturally acquired leishmaniasis. Antimicrob Agents Chemother 48:641-643.

Allefs S, Florack DEA, Hoogendoorn C, Stiekema WJ (1995) Erwinia soft rot resistance of potato cultivars transformed with a gene construct coding for antimicrobial peptide cecropin B is not altered. Am Potato J 72:437-445.

Bohlmann H (1999) The role of thionins in the resistance of plants. In: S.K. Datta and S. Muthudrishan (eds.) Pathogenesis-Related Proteins in Plants. CRC Press, New York, pp 207-234.

Boman HG (1995) Peptide antibiotics and their role in innate immunity. Annu Rev Immunol 13:61-92.

Boman HG, Steiner H (1981) Humoral immunity in Cecropia pupae. Curr Topics Microbiol Immunol 94:75-91.

Bradford M (1976) A rapid and sensitive method for the quentification of microgram quantities utilizing the principle of protein-dye binding. Anal Biochem 72:248-254.

Broekaert WF, Terras FRG, Cammue BP, Osborn RW (1995) Plant defensins: Novel antimicrobial peptides as components of the host defense system. Plant Physiol 108: 1353-1358.

Broglie K, Chet I, Holliday M, Cressman R, Riddle P, Knowlton S, Mauvais CJ, Broglie R (1991) Transgenic plants with enhanced resistance to the fungal pathogen Rhizoctonia solani. Science 254:1194-1197.

Cao H, Li X, Dong X (1998) Generation of broad-spectrum disease resistance by overexpression of an essential regulatory gene in systemic acquired resistance. Proc Natl Acad Sci USA 95:6532-6536.

Castro MS, Fontes W (2005) Plant defense and antimicrobial peptides. Protein and Peptide Lett 12:13-18.

Cavallarin L, Andreu D, San Segundo B (1998) Cecropin A-derived peptides are potent inhibitors of fungal plant pathogens. Mol Plant-Microbe Interact 11:218-227. 
Christensen AH, Scharrock RA, Quail PJ (1992) Maize polyubiquitin genes: structure, thermal perturbation of expression and transcript splicing, and promoter activity following transfer to protoplasts by electroporation. Plant Mol Biol 18:675-689.

Christensen AH, Quail PH (1996) Ubiquitin promoter based vectors for high level expression of selectable and/or screenable marker genes in monocotyledoneus plants. Transgenic Res 5:216-218.

Christensen B, Fink J, Merrifield RB, Mauzerall D (1988) Channel-forming properties of cecropins and related model compounds incorporated into planar lipid membranes. Proc Natl Acad Sci USA 85:5072-5076.

Coca M, Bortolotti C, Rufat M, Peñas G, Eritja R, Tharreau D, Martinez del Pozo A, Messeguer J, San Segundo B (2004) Transgenic rice plants expressing the antifungal AFP protein from Aspergillus giganteus show enhanced resistance to the rice blast fungus Magnaporthe grisea. Plant Mol Biol 54:245-259.

Cornelissen BJC, Horowitz J, van Kan JAL, Goldberg RB, Bol JF (1987) Structure of tobacco genes encoding pathogenesis-related proteins from the PR-1 group. Nucl Acid Res 15:6799-6811.

Datta S, Muthukrisnan S, Datta SK (1999) Expression and function of PR proteins in transgenic plants. In: S.K. Datta and S. Muthudrishan (Ed.), Pathogenesis-Related Proteins in Plants. CRC Press, New York pp 261-277.

Florack D, Allefs S, Bollen R, Bosch D, Visser B, Stiekema W (1995) Expression of giant silkmoth cecropin B genes in tobacco. Transgenic Res 4:132-141.

Hightower R, Baden C, Penzes E, Dunsmuir P (1994) The expression of cecropin peptide in transgenic tobacco does not confer resistance to Pseudomonas syringae pv tabaci. Plant Cell Reports 13:295-299.

Hood EE, Gelvin SB, Melchers LS, Hoekema A (1993) New Agrobacterium helper plasmids for gene transfer to plants. Transgenic Res 2:208-218.

Huang Y, Nordeen RO, Di M, Owens LD, McBeath JH (1997) Expression of an engineered cecropin gene cassette in transgenic tobacco plants confers disease resistance to Pseudomonas syringae pv. tabaci. Phytopathology 87:494-499.

Jach G, Gornhardt B, Mundy J, Logemann J, Pinsdorf E, Leah R, Schell J, Maas C (1995) Enhanced quantitative resistance against fungal disease by combinatorial 
expression of different barley antifungal proteins in transgenic tobacco. Plant J 8:97103.

Jaynes JM, Burton CA, Barr SB, Jeffers GW, Julian GR, White KL, Enright FM, Klei TR, Laine RA (1988) In vitro cytocidal effect of novel lytic peptides on Plasmodium falciparum and Trypanosoma cruzi. FASEB J. 2:2878-2883.

Jaynes JM, Nagpala P, Destéfano-Beltrán L, Huang J-H, Kim J, Denny T, Cetiner S (1993) Expression of a cecropin B lytic peptide analog in trangenic tobacco confers enhanced resistance to bacterial wilt caused by Pseudomonas solanacearum. Plant Sci 89:43-53.

Iwai H, Nakajima Y, Natori S, Arata Y, Shimada I (1993) Solution conformation of an antibacterial peptide, sarcotoxin IA, as determined by ${ }^{1} \mathrm{H}-\mathrm{NMR}$. Eur J Biochem 217:639-644.

Liu Q, Feng Y, Zhao X, Dong H, Xue Q (2004). Synonymous codon usage bias in Oryza sativa. Plant Sci 167:101-105.

Logeman J, Schell J, Willmitzer L (1987) Improved method for the isolation of RNA from plant tissues. Anal Biochem 163:16-20.

Lorito M, Woo SL, García-Fernandez I, Colucci G, Harman GE, Pintor-Toro JA, Filippone E, Muccifora S, Lawrence CB, Zoina A, Tuzun S, Scala F (1998) Genes from mycoparasitic fungi as a source for improving plant resistance to fungal pathogens. Proc Natl Acad Sci USA 95:7860-7865.

Mittler R, Shulaev V, Lam E (1995) Coordinated activation of programmed cell death and defense mechanisms in transgenic tobacco platns expressing a bacterial proton pump. Plant Cell 7:29-42.

Mills D, Hammerschlag FA (1993) Effect of cecropin B on peach pathogens, protoplasts, and cells. Plant Sci 93:143-150.

Mills D, Hammerschlag FA, Nordeen RO, Owens LD (1994) Evidence for the breakdown of cecropin B by proteinases in the intercellular fluid of peach leaves. Plant Sci 104:17-22.

Mitsuhara I, Matsufuru H, Ohshima M, Kaku H, Nakajima Y, Murai N, Natori S, Ohashi Y (2000) Induced expression of sarcotoxin IA enhanced host resistance against both bacterial and fungal pathogens in transgenic tobacco. Mol PlantMicrobe Interact 13:860-868. 
Molina A, Ahl Goy P, Fraile A, Sánchez-Monje R, García-Olmedo F (1993) Inhibition of bacterial and fungal plant pathogens by thionins types I and II. Plant Sci 92:169177.

Moreno AB, Martinez del Pozo A, Borja M, San Segundo B (2003) Activity of the antifungal protein from Aspergillus giganteus against Botrytis cinerea. Phytopathology 93:1344-1353.

Murray MG, Thompson WF (1980) Rapid isolation of high molecular weight plant DNA. Nucl Acid Res 8:4321-4325.

Nordeen RO, Sinden SL, Jaynes JM, Owens LD (1992) Activity of cecropin SB37 against protoplasts from several plant species and their bacterial pathogens. Plant Sci 82:101-107.

Osusky M, Zhou G, Osuska L, Hancock E, Kay WW, Misra S (2000) Transgenic plants expressing cationic peptide chimeras exhibit broad-spectrum resistance to phytopathogens. Nature Biotech 18:1162-1166.

Osusky M, Osuska L, Hancock RE, Kay WW, Misra S (2004) Transgenic potatoes expressing a novel cationic peptide are resistant to late blight and pink rot. Transgenic Res 13:181-190.

Ou SH (1985) Rice Diseases, 2nd ed. Commonwealth Mycological Institute, Kew England.

Owens LD, Heutte TM (1997) A single amino acid substitution in the antimicrobial defense protein cecropin $\mathrm{B}$ is associated with diminished degradation by leaf intercellular fluid. Mol Plant-Microbe Interact 10:525-528.

Pons MJ, Marfà V, Melé E, Messeguer J (2000) Regeneration and genetic transformation of Spanish rice cultivars using mature embryos. Euphytica 114:117122.

Prodromou Ch, Pearl LH (1992) Recursive PCR: a novel technique for total gene synthesis. Protein Engineering 5:827-829.

Rao AG (1995) Antimicrobial peptides. Mol Plant-Microbe Interact 8:6-13.

Reed WA, Elzer PH, Enright FM, Jaynes JM, Morrey JD, White KL (1997) Interleukin 2 promoter/enhancer controlled expression of a synthetic cecropin-class lytic peptide in transgenic mice and subsequent resistance to Brucella abortus. Transgenic Res $6: 337-347$ 
Schägger H, von Jagow G (1987) Tricine-sodium dodecyl sulfate-polyacrylamide gel electrophoresis for the separation of proteins in the range from 1 to $100 \mathrm{kDa}$. Anal Biochem 166:368-379.

Sharma A, Sharma R, Imamura M, Yamakawa M, Machii H (2000) Transgenic expression of cecropin B, an antibacterial peptide from Bombyx mori, confers enhanced resistance to bacterial leaf blight in rice. FEBS Let 484:7-11.

Shai Y (1999) Mechanism of the binding, insertion and desestabilization of phospholipid bilayer membranes by alpha-helical antimicrobial and cell nonselective membrane-lytic peptides. Biochem Biophys Acta 1462:55-70.

Silvestro L, Axelsen PH (2000) Membrane-induced folding of cecropin A. Biophys J 79:1465-1477.

Steiner H, Hultmark D, Engström A, Bennich H, Boman HG (1981) Sequence and specificity of two antibacterial proteins involved in insect immunity. Nature 292:246-248.

Steiner H, Andreu D, Merrifield RB (1988) Binding and action of cecropin and cecropin analogs: Antibacterial peptides from insects. Biochim Biophys Acta 939:260-266.

Vila L, Lacadena V, Fontanet P, Martinez del Pozo A, San Segundo B (2001) A protein from the mold Aspergillus giganteus is a potent inhibitor of fungal plant pathogens. Mol Plant-Microbe Interact 14:1327-1331.

Zhu Q, Maher EA, Masoud S, Dixon RA, Lamb CJ (1994) Enhanced protection against fungal attack by constitutive co-expression of chitinase and glucanase genes in transgenic tobacco. Bio/Technology 12:807-812.

Zasloff M (2002) Antimicrobial peptides of multicellular organisms. Nature 415:389395. 


\section{Figure Legends}

Fig. 1a, b Synthetic cecropin A genes and plant expression vectors used for rice transformation. a Construction of the synthetic cecropin A genes by recursive PCR. In the two synthetic cecropin A genes, the Ap-CecA and ER-CecA genes, the signal peptide from the tobacco $P R-1 a$ gene was fused to the mature cecropin A peptide. Arrows indicate the position of the overlapping oligonucleotides used for the synthesis of the cecropin A genes. Ap, apoplast; ER, endoplasmic reticulum; KDEL, endoplasmic retention signal. b Schematic diagrams of the plant expression vectors used for rice transformation, the pCubi::Ap-CecA::nos and pCubi::ER-CecA::nos vectors. Expression of the cecropin A genes is driven by the maize ubiquitin (ubi) promoter and the nos terminator. The hptII gene encoding resistance to hygromycin serves as a selectable marker for rice transformation. 35SCaMV, 35S promoter from cauliflower mosaic virus. RB, right border; LB, left border.

Fig. 2a, b Northern blot analysis of transgenic rice plants. Analysis of total RNA (10 :g) obtained from leaves of hygromycin-resistant T0 plants harbouring the $p C u b i:: A p$ CecA::nos (a) or the pCubi::ER-CecA::nos (b) construct (R26 and R33 code, respectively). RNAs were separated in a formaldehyde/agarose gel, transferred onto nylon membranes and hybridized to a ${ }^{32}$ P-labeled cecropin A probe. Lane (wt), untransformed senia control. Lower panels show ethidium bromide staining of the corresponding RNA samples.

Fig. 3a-c Protein and RNA blot analysis of T2 homozygous plants expressing the ApCec $A$ or the $E R-C e c A$ gene. a Immunological detection of the cecropin A peptide in protein extracts from leaves of Ap-CecA (lines R26-2, R26-9 and R26-14) or ER-CecA (lines R33-7, R33-23 and R33-24) plants. Leaf extracts (100 $\mu \mathrm{g}$ ) were separated on Tricine-SDS-PAGE. Lane wt, untransformed rice plants. Lane Cec A, pure cecropin A peptide (Sigma) $(0.1 \mu \mathrm{g})$. The position of the cecropin A peptide is indicated by arrows. b Northern blot analysis of T2 homozygous $A p-C e c A$ and ER-CecA rice plants. The middle panel shows ethidium bromide staining of RNA samples analyzed. The lower 
panel shows the normalized cecropin A transcript level for each RNA sample. c RNA blot analysis of the expression of the rice $P R-1$ gene in cecropin A-expressing lines. Infection was conducted for 3 days in a detached leaf assay using a $10^{6}$ spores $/ \mathrm{ml}$ inoculum. Line C, control, non-infected wild type plants; Lane I, M. grisea-infected wild-type plants.

Fig. 4a-h Immunolocalization of cecropin A in transgenic rice. Transverse sections were prepared from the radicle of 2 day-old seedlings of Ap-CecA (line R26-14, a and $\mathbf{b} ; \mathbf{g}$ and $\mathbf{h}$ ) and ER-CecA (line R33-7, $\mathbf{c}$ and $\mathbf{d}$ ) lines, and from control untransformed seedlings (e and $\mathbf{f})$. Sections were incubated with the anti-cecropin A antiserum (a, b, c and e) or the preimmune serum (g). Shown are confocal (a, b, c, e and g) and transmission (d, f and $\mathbf{h}$ ) microscopical images. Bars = 20 :m.

Fig. 5a-d In vitro antifungal activity of cecropin A (a) and protein extracts prepared from leaves of transgenic rice (b-d). a $M$. grisea was grown in the presence of increasing concentrations of Cecropin A (2, 4 and $10: \mathrm{M})$ that have been mixed (black bars), or not (white bars), with total protein extracts obtained from leaves of control untransformed plants (100 $\mu \mathrm{g}$ each protein extract). Fungal growth in the absence of cecropin A was taken as $100 \%$. b. Effect of total protein extracts (100 $\mu \mathrm{g}$ each) prepared from T2 homozygous transgenic Ap-CecA (lines R26-9 and R26-14) and ER-CecA (lines R33-7 and R33-24) plants on M. grisea growth. Fungal growth in the presence of protein extracts from control untransformed rice plants (WT) was taken as $100 \%$. c Fungal growth in the presence of intercellular fluids $(20 \mu \mathrm{g})$ obtained from leaves of transgenic lines shown in B. Percentage of the growth in presence of ICFs from WT plants is shown. d. Fungal growth in the presence of intracellular proteins (20 $\mu \mathrm{g})$. After extraction of the ICFs from leaves of transgenic lines (shown in C), the leaves were used for preparation of protein extracts and their antifungal activities were determined. Values in the four panels represent the mean and the standard deviations of three replicas after $48 \mathrm{~h}$ of incubation. Results from one representative example out of three experiments are shown.

Fig. 6a, b Resistance in transgenic rice plants expressing the cecropin A gene. 
a Detached leaves from control untransformed Senia plants, $A p-C e c A$ and $E R-C e c A$ rice lines (T2 homozygous lines) were locally inoculated with $M$. grisea spores. The concentration of inoculum is indicated on the left. Appareance of disease symptoms 7 days after inoculation (dpi) of leaves from control untransformed Senia plants (WT), Ap-CecA plants (R26-14 and R26-9) and ER-CecA plants (R33-7 and R33-24) are presented. This experiment is one of the four performed which gave similar results. The other Ap-CecA and ER-CecA lines showed levels of protection comparable to those here presented. b Representative trypan blue staining of leaves inoculated with $M$. grisea spores. The leaf tissue in control Senia plants (WT) was fully colonized by mycelium (left panel). The fungus produced conidia on the infected leaves of control plants (left panel, inset). Under the same experimental conditions, no hyphae or hyphae showing abnormal morphology were detected in the leaf tissue of Ap-CecA (line R26-14, middle panel) and ER-CecA (line R33-24, right panel) rice lines. Staining was carried out 7 days after inoculation with fungal spores. Bars $=100$ :m.

Fig. 7 Phenotype of ER-CecA and Ap-CecA rice plants (T2 homozygous lines) and control untransformed Senia plants (wt) challenged with $M$. grisea. Plants at the threeleaf stage were sprayed with a suspension of $M$. grisea spores $\left(10^{4}\right.$ spores $\left./ \mathrm{ml}\right)$. Picture was taken at 30 days after inoculation. 
a

$\stackrel{\text { CecA.1 }}{\underset{\text { CecA.2 }}{\longrightarrow}} \frac{\text { CecA.3 }}{\stackrel{\text { CecA.4 }}{\rightleftarrows}}$

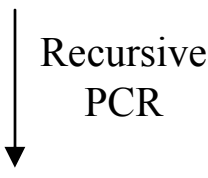

BamHI

\begin{tabular}{|c|} 
Ap-Cec $\boldsymbol{A}$ \\
\hline$P R-1 a \square \quad C e c A$ \\
\hline
\end{tabular}

Ap-CecA ER-CecA

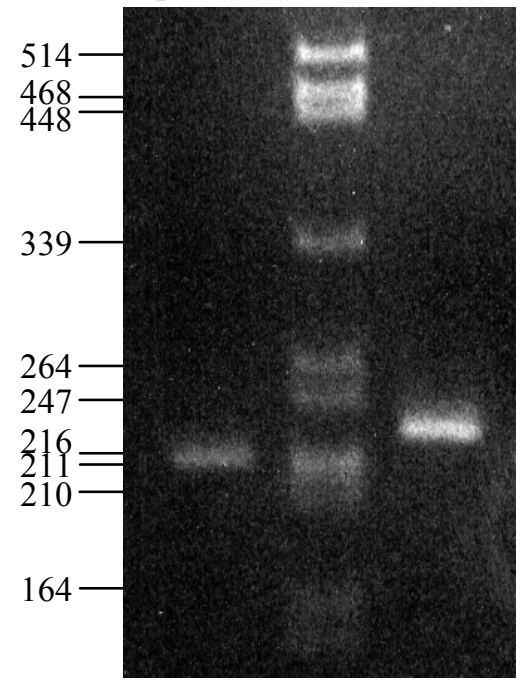

Recursive

PCR

BamHI BamHI

\begin{tabular}{|c|c|}
\multicolumn{3}{|c|}{ ER-CecA } \\
\hline$P R-1 a \square \quad C e c A$ \\
\hline $\mathrm{KDEL}$
\end{tabular}

\section{b}

pCubi::Ap-CecA::nos

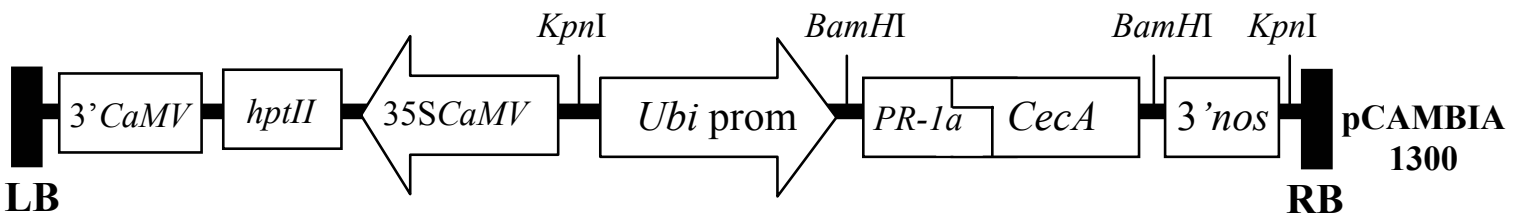

\section{pCubi::ER-CecA::nos}

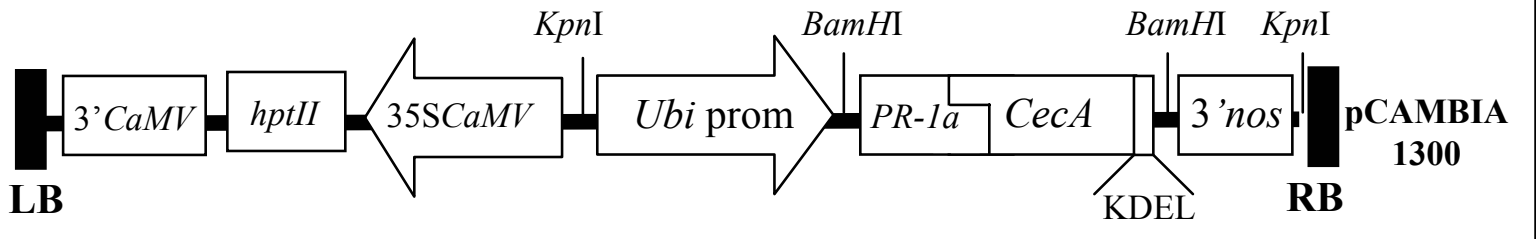




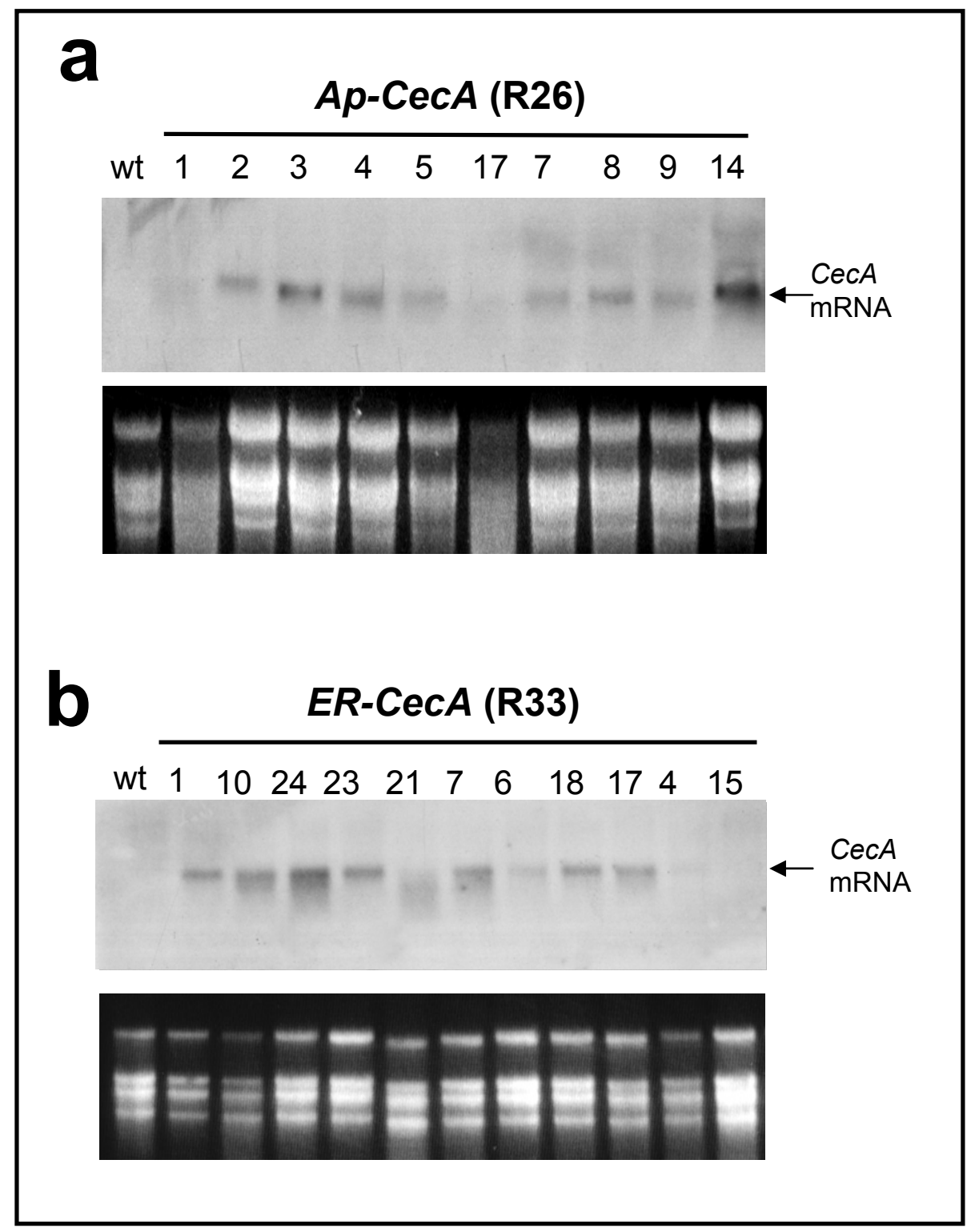

Figure 2 


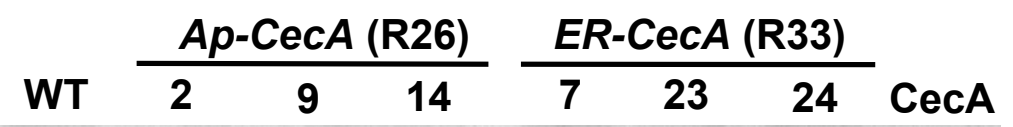

14 -

$5.6-$

b
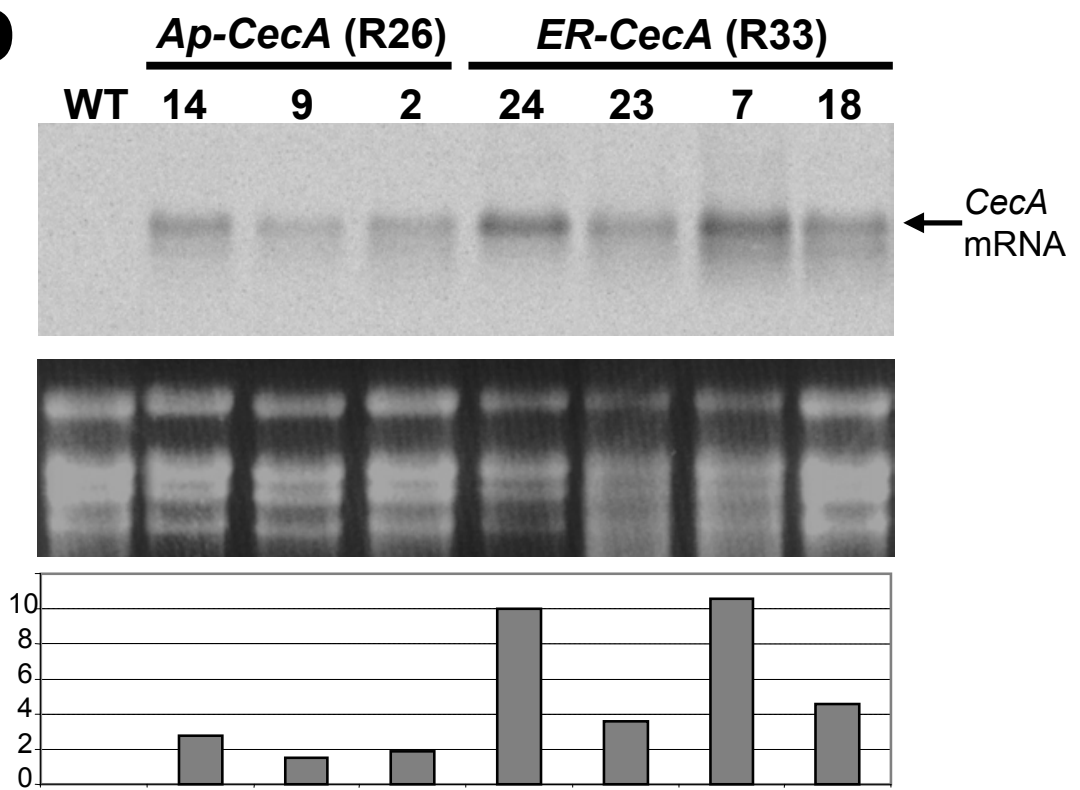

C

$$
\begin{aligned}
& \text { WT Ap-CecA (R26) ER-CecA (R33) }
\end{aligned}
$$

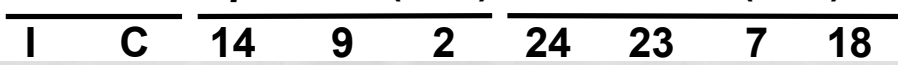

PR1a

mRNA $\longrightarrow$

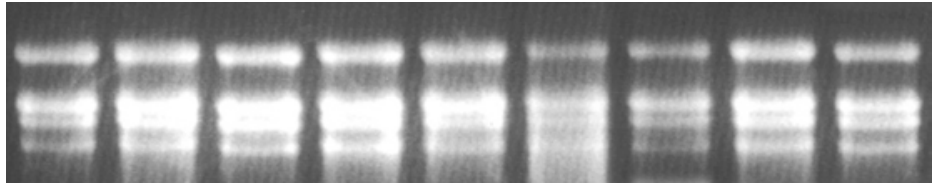

Figure 3 


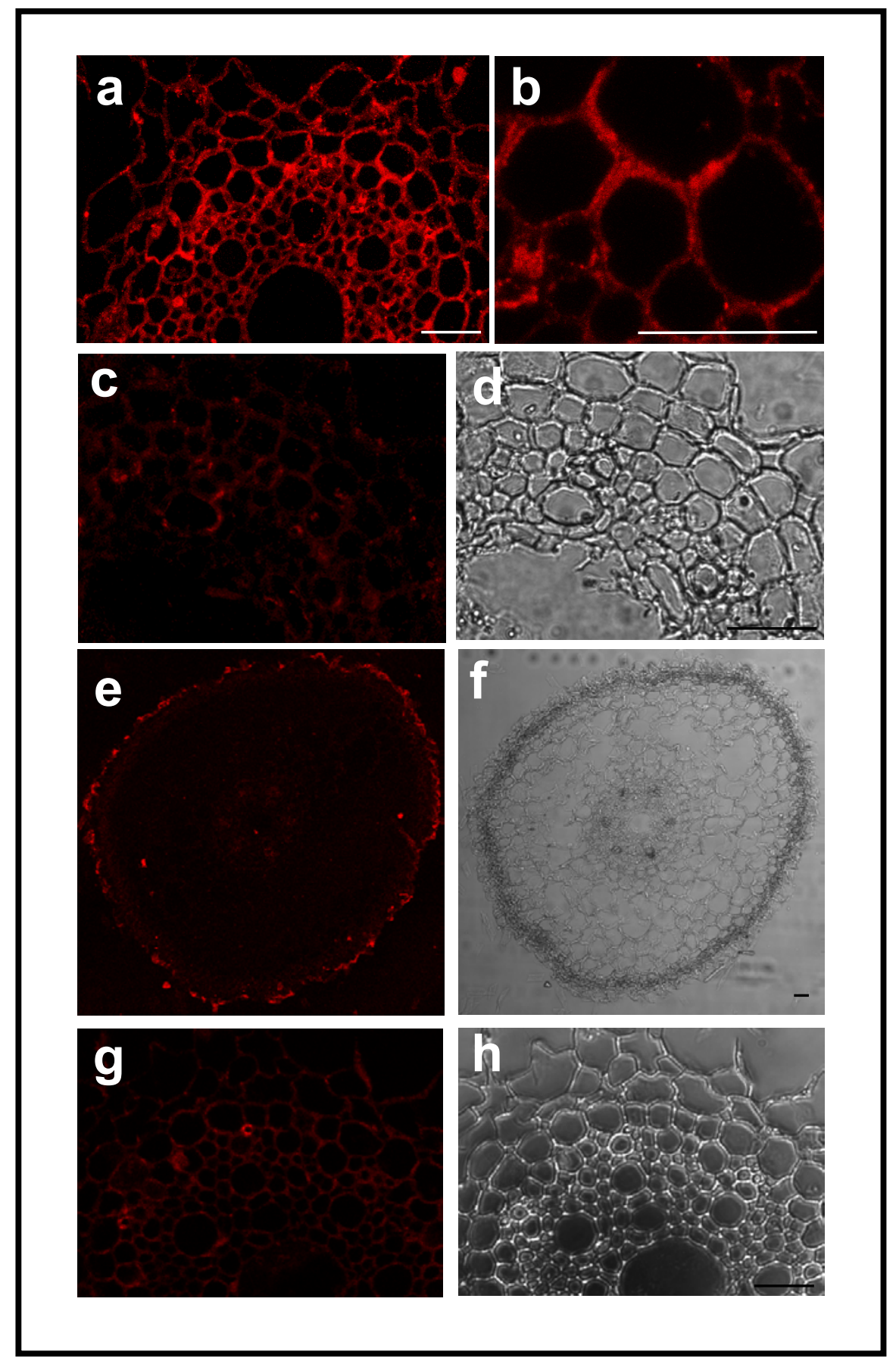

Figure 4 

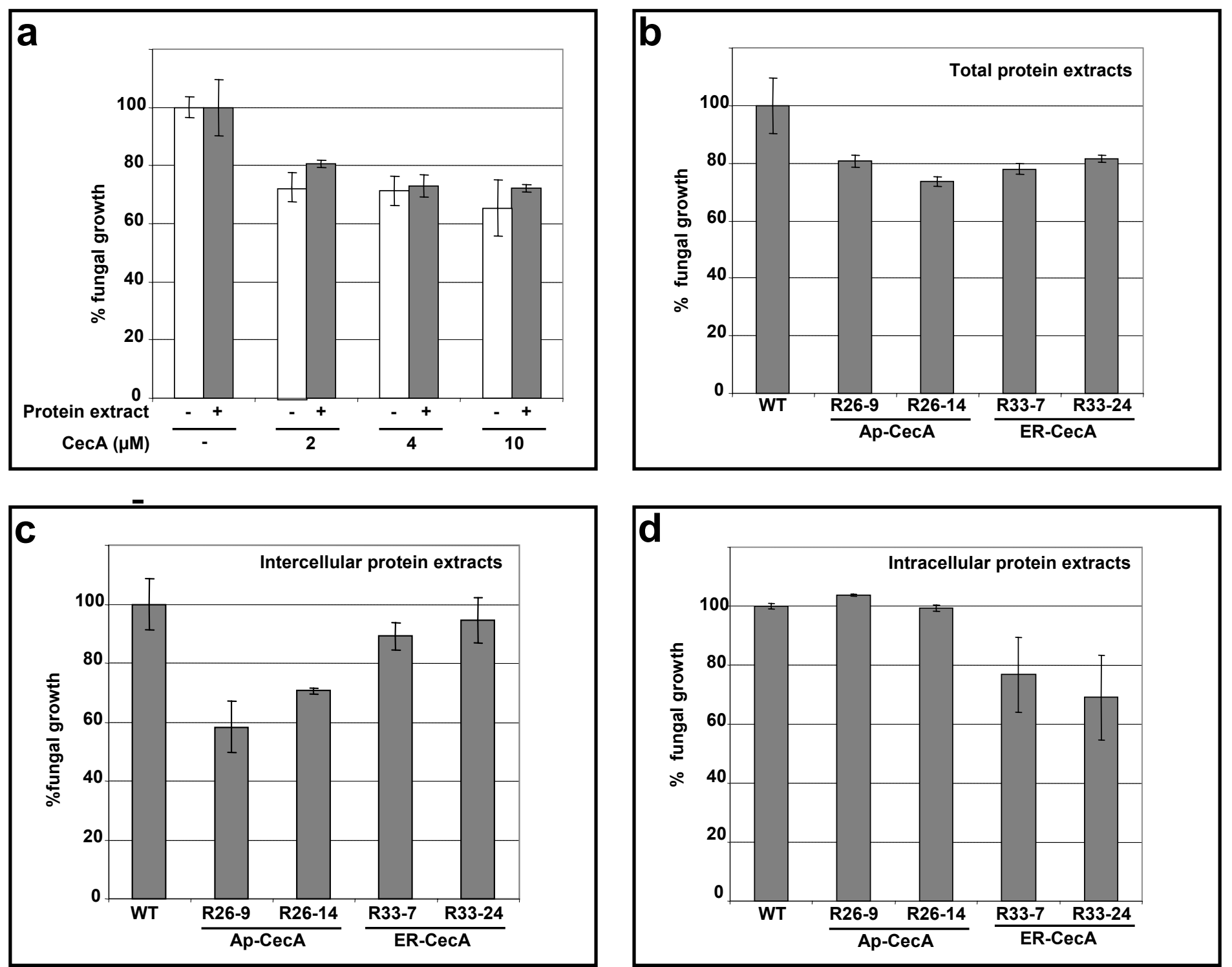

Figure 5 

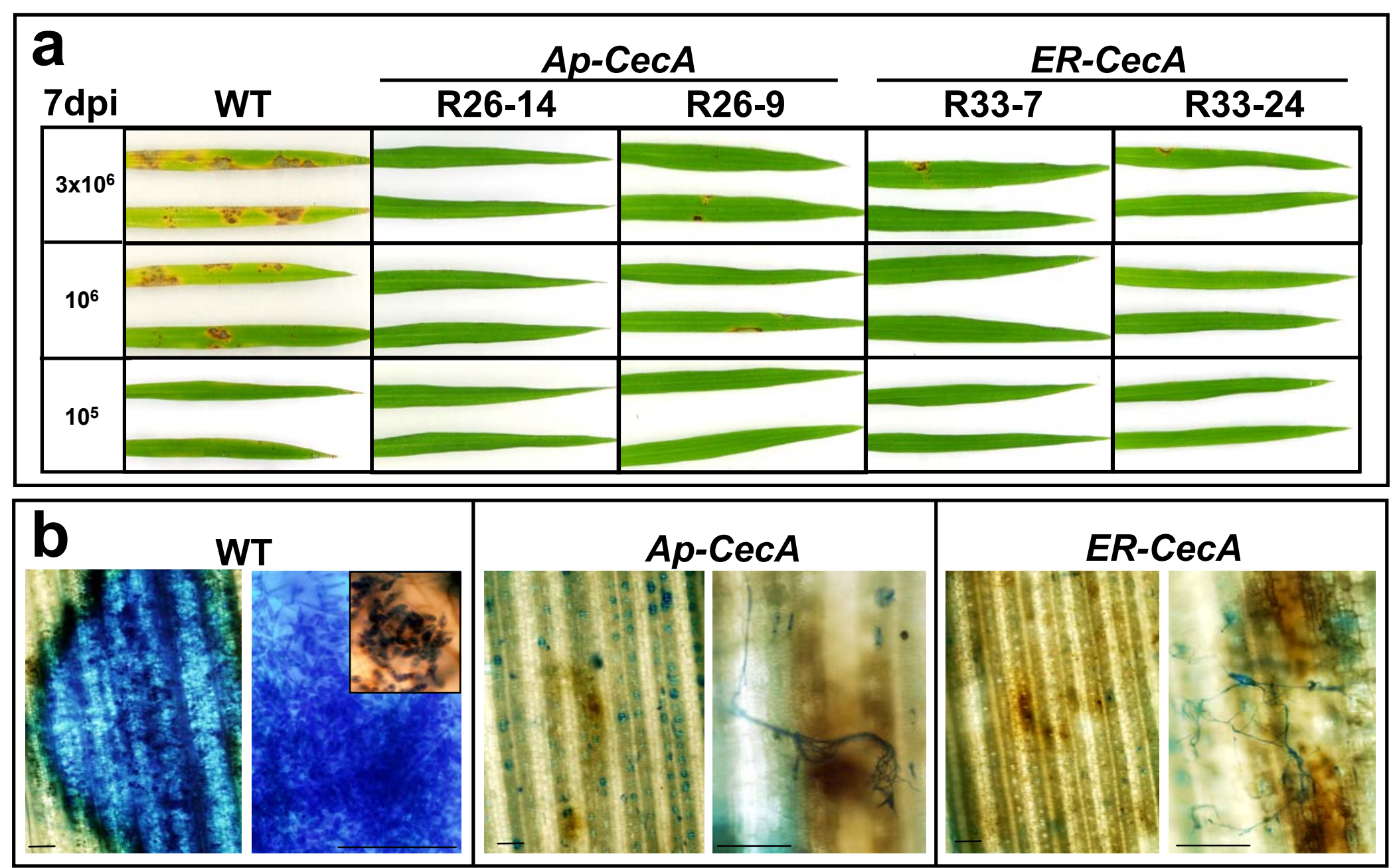

Figure 6 


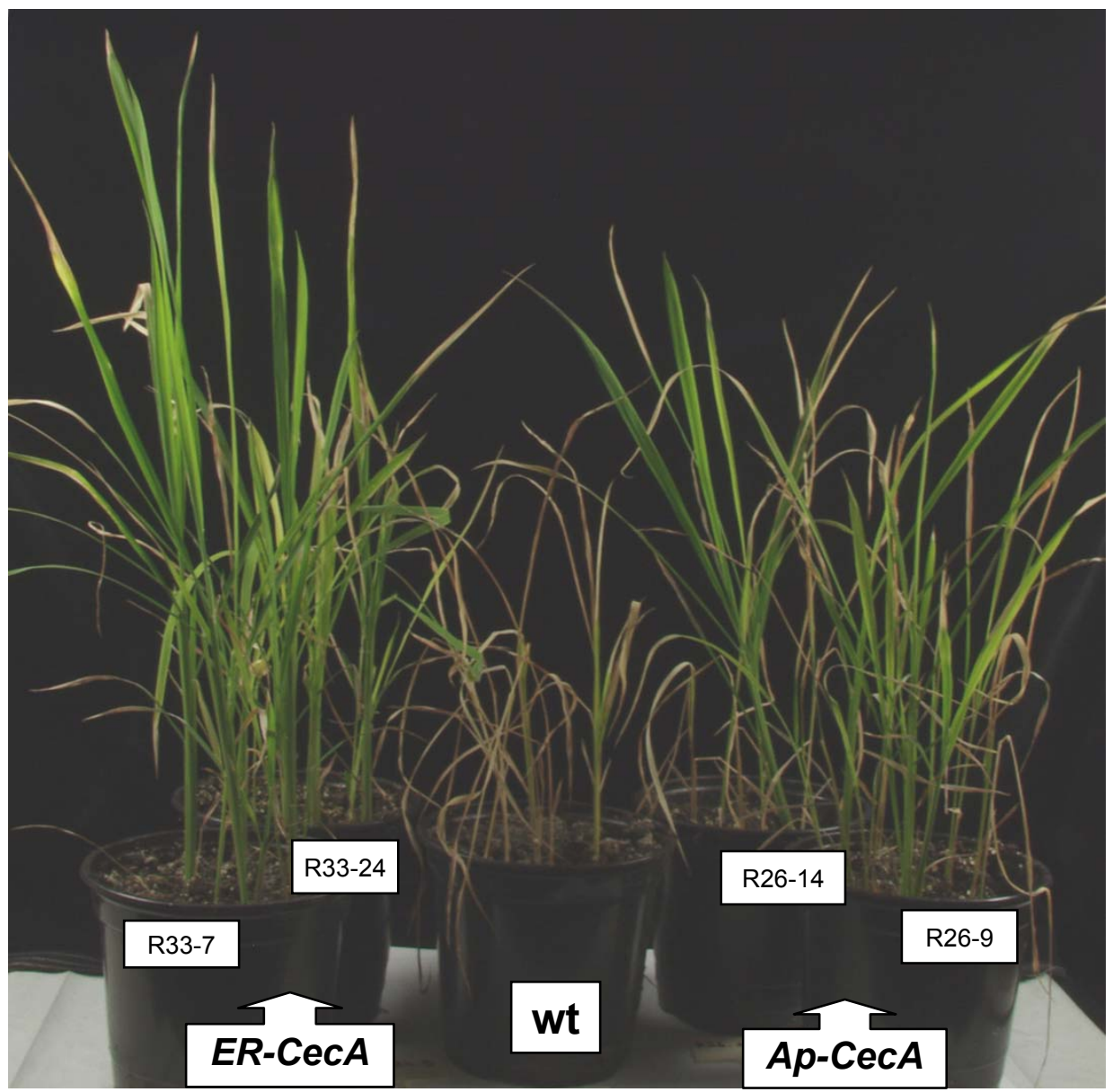

Figure 7 
Table 1. In vivo fungal bioassys of transgenic rice plants. Untransformed control plants (WT) and transgenic plants homozygous for the cecropin A gene, Ap-CecA and ERCecA lines, were infected with $M$. grisea. Values given are the mean and standard deviation of two independent experiments.

\begin{tabular}{|l|l|l|l|}
\hline Line & Lesion size $(\mathrm{cm})^{\mathrm{a}}$ & Spore number $^{\mathrm{b}}$ & \% of survival $^{\mathrm{c}}$ \\
\hline WT & $0.996 \pm 0.19$ & $292,500 \pm 116,865$ & $15.278 \pm 2.4$ \\
\hline R26-2 (Ap-CecA) & $0.326 \pm 0.29$ & $8,000 \pm 7,211$ & - \\
\hline R26-9 (Ap-CecA) & $0.118 \pm 0.10$ & $3,733 \pm 1,270$ & $91.66 \pm 11.78$ \\
\hline R26-14 (Ap-CecA) & $0.098 \pm 0.06$ & $1,000 \pm 1,730$ & $73.33 \pm 9.42$ \\
\hline R33-7 (ER-CecA) & $0.151 \pm 0.10$ & 0 & $93.75 \pm 8.82$ \\
\hline R33-23 (ER-CecA) & $0.128 \pm 0.24$ & $2,333 \pm 3,214$ & - \\
\hline R33-24 (ER-CecA) & $0.075 \pm 0.08$ & 0 & $91.66 \pm 11.78$ \\
\hline
\end{tabular}

${ }^{a}$ Infection with M. Grisea spores was accomplished using the detached leaf assay using a spore suspension of $1 \times 10^{6}$ spores/ml. Two inoculations were made at the second leaf of 2 week-old rice plants. Three individual leaves from at least three plants for each independent transgenic line were used. Lesions were measured 7 days after inoculation.

${ }^{\mathrm{b}}$ Infection was measured by counting the number of spores produced in leaves from control and transgenic lines using the detached leaf assay. Three independent leaves and three inoculations per leaf were made $\left(1 \times 10^{6}\right.$ spores $\left./ \mathrm{ml}\right)$. Spores were harvested in $1 \mathrm{ml}$ of steril water 6 days after infection. Three counts (10 $\mu \mathrm{l}$ of each sample) were made to calculate the number of spores per ml.

c Soil-grown plants were sprayed with a suspension of $M$. grisea spores as described in Figure 6. At least 6 plants for each transgenic line were used. The percentage of survival of control and transgenic plants was determined 30 days after inoculation with fungal spores. 